\title{
Children under five years of age in senegal: A group highly exposed to respiratory viruses infections
}

\author{
Amary Fall ${ }^{1}$, Assane Dieng' 2 , Serigne Fallou Wade ${ }^{3}$, Abdoulaye Diop ${ }^{2}$, Jean Baptisse Niokhor Diouf ${ }^{4}$, Djibril Boiro ${ }^{5}$, Younoussa Keita ${ }^{6}$, \\ Assane Sylla ${ }^{5}$, Ousmane Ndiaye ${ }^{5}$, Cheikh Saad Bouh Boye ${ }^{2}$, Mbayame Niang ${ }^{*}$ and Ndongo Dia ${ }^{1 *}$ \\ ${ }^{1}$ Pole de virologie, Institute Pasteur, Dakar, Senegal \\ ${ }^{2}$ Bacteriology and Virology Laboratory, Dantec teaching Hospital, Dakar, Senegal \\ ${ }^{3}$ Li Ka Shing Knowledge Institute, St. Michael's Hospital 209 Victoria St. Toronto, Canada \\ ${ }^{4}$ Pediatric unit Roi BAUDOUIN hospital, Dakar, Senegal \\ ${ }^{5}$ Pediatric Unit, Abass NDAO teaching Hospital, Dakar, Senegal \\ ${ }^{6}$ Pediatric unit, Aristide Le Dantec Hospital, Senegal
}

\begin{abstract}
Background: Acute respiratory infections (ARI) continue to be the leading cause of pediatric morbidity and mortality worldwide.

Objectives: The present study is a prospective analysis of the prevalence and diversity of respiratory viruses associated with acute RTIs in children under 5 years of age in Senegal, and their association with disease severity.

Patients/Methods: An active surveillance of ARI was conducted from March 2014 to December 2015 in three pediatric referral Healthcare departments of Dakar. 288 children with ARI were enrolled and respiratory specimens collected. A two-step multiplex real-time RT-PCR for the simultaneous testing of 16 different respiratory viruses was performed.

Results: 93 children required hospitalization. Viral etiologies were identified in 224 patients while 64 were negative for all tested viruses. Single viral infections accounted for $30.5 \%$ and co-infections for $46.9 \%$. A total of 439 respiratory viruses were identified in all children. Among these, 154 (35.3\%) were detected in hospitalized children. Adenoviruses with $44.4 \%$, influenza viruses $36.5 \%$, rhinoviruses (HRV) $28.5 \%$, enteroviruses $19.8 \%$ and respiratory syncytial virus (RSV) with $10.1 \%$ were the most detected. RSV infections were significantly more frequent in the first 6 months of life ( $\mathrm{p}$-value $=0.00213$ ). RSV and HRV are mostly associated with bronchiolitis and bronchitis. Influenza detection is also the most related with pneumonia disease $(47.6 \%)$.
\end{abstract}

Conclusion: This study investigated the role of 16 different respiratory viruses in children with ARI in this Senegal. Data clearly suggest that respiratory viruses are major contributors to childhood acute respiratory infections in Senegal.

\begin{abstract}
Abbreviations: ARI: Acute respiratory infection; RTI: respiratory tract infection; RT-PCR: Reverse Transcription Polymerase Chain Reaction; RSV: respiratory syncytial virus; HRV: human rhinoviruses; ILI: Influenza-like Illness; HAdV: human adenovirus; HEV: human enterovirus; HMPV: human metapneumovirus; HCoV: human coronaviruses; PIV: parainfluenza virus; LRTI: lower respiratory tract infections; URTI: upper respiratory tract infections; CRP: C-reactive protein; CBC: complete blood count; WHO: World Health Organization; MoH: Ministry of Health; IPD: Institut Pasteur de Dakar.
\end{abstract}

\section{Background}

Acute respiratory infections (ARI) continue to be the leading cause of pediatric morbidity and mortality worldwide [1,2]. In 2010, Nair and colleagues reported that 11.9 million and 3.0 million episodes of severe and very severe ARI respectively, contributed to childhood hospitalization [3]. Furthermore, 0.935 million deaths in 2013 were attributed to ARI [4]. In developing countries where pneumonia is responsible over $10-25 \%$ of all deaths among children under 5 years of age the situation is more alarming [5]. Within the etiology of ARIs, viruses play an important role and are the main cause of ARIs in children under the age of 5 [6]. Unfortunately, in some cases, they also become an important cause of death [7]. In Senegal, recent data collected in the framework of the sentinel surveillance of respiratory viruses have shown a variety of respiratory viruses circulating in the community [8]. The most common viruses associated with influenza-like illness (ILI) in patients were influenza viruses, adenoviruses (ADVs), human rhinoviruses (HRVs), respiratory syncytial virus (RSV), enteroviruses (EVs), parainfluenza viruses (PIVs), human metapneumovirus (hMPV), and human coronaviruses (HCoVs) 229E, OC43, NL63, and HKU1. Studies focused on HRV and RSV, have revealed a high activity of both viruses in children under 5 in Senegal, especially during the rainy season $[9,10]$. Indeed, previous studies have well established that RSV is the leading cause of lower respiratory tract infections (LRTIs)

Correspondence to: Dr Ndongo Dia, Pediatric unit, Aristide Le Dantec Hospital, Senegal, Tel: +221 83992 25; Fax: + 2213383992 24; E-mail: ndia@pasteur.sn

Dr Mbayame Niang, Pediatric unit, Aristide Le Dantec Hospital, Senegal, Tel: +221 8399222 ; E-mail: niang@pasteur.sn

Key words: epidemiology, adenoviruses, respiratory syncytial virus, influenza viruses, rhinoviruses, prevalence

Received: July 16, 2017; Accepted: August 04, 2017; Published: August 04, 2017 
in young children with $50 \%$ of children infected during their first year of life, and $100 \%$ having experienced at least one infection by 3 years of age [11]. Human rhinoviruses (HRV) were known as a frequent cause of upper respiratory tract infections (URTI). However, recently, HRV were found also to be associated with lower respiratory infections (LRTI), such as bronchiolitis [12], pneumonia, exacerbation of asthma or cystic fibrosis, $[13,14]$ chronic obstructive pulmonary disease [15], and also hospitalization of children [16].

The present study is a prospective exploration of the prevalence and diversity of respiratory viruses associated with acute RTIs in children under 5 years of age, and their association with disease severity (clinical diagnostic).

\section{Materials and methods}

\section{Samples and data collection}

This prospective study was conducted from March 2014 to December 2015, and consisted of an active surveillance of ARI in three pediatric referral Healthcare departments of Dakar (Hôpital Aristide Ledantec, Hôpital Roi Baudoin and Hôpital Abass Ndao). A clinical team at each hospital was trained on the case definition identification and surveillance procedures; patients'carers/tutors were asked for verbal consent to participate. The clinical team enrolled any patients presented at the hospital who met an ARI case definition. ARI was defined as any patient with sudden onset of one or more of the following symptoms and signs: rhinitis, cough, sore throat, wheeze, dyspnea associated or not with an axillary temperature of more than $38.5^{\circ} \mathrm{C}$. A respiratory specimen (nasal and / or throat swab) was collected from each child up to 5 years of age and placed in 2-mL cryovials containing viral transport medium (Universal Transport Medium; COPAN Diagnostics Inc., Murrieta, CA) and immediately transported at $4^{\circ} \mathrm{C}$ to the laboratory. At the laboratory, the specimens were processed immediately for viral diagnostic. Aliquots of each sample were also stored at $-80^{\circ} \mathrm{C}$ for additional analysis.

Data regarding hospitalized patients were collected from medical records, using a standardized report form that includes basic epidemiologic data and a description of the symptoms prior to presentation. For hospitalized children, an input record was routinely performed including a complete blood count $(\mathrm{CBC})$, a $C$-reactive protein CRP and radiography in the case of pulmonary signs. Case reports were entered into an Epi Info database (Centers for Disease Control and Prevention, Atlanta, GA) and merged with laboratory data.

\section{PCR assay for respiratory viruses diagnostic}

Total Viral nucleic acid (RNA/DNA) was obtained from $140 \mu \mathrm{l}$ of clinical specimen using a Viral Nucleic Acid Extraction kit (QIAGEN, Valencia, CA, USA) according to the manufacturer's recommendation. RNA are eluted with $60 \mu \mathrm{l}$ nuclease-free water and stored at $-80^{\circ} \mathrm{C}$ until use. A two-step multiplex real-time RT-PCR was performed with a Bio-Rad CFX-96 thermocycler (Bio-Rad Laboratories) as previously described [8] for the simultaneous testing for Influenza viruses (fluA and fluB), Human respiratory syncytial virus (RSVA and RSVB), Human adenoviruses (HAdV), Human metapneumovirus (HMPV), Human coronaviruses (229E, NL63, OC43), Human parainfluenza viruses (PIV1, -2, -3 and -4), Human rhinoviruses (HRV), Human enteroviruses (HEV) and Human bocaviruses (HBoV).

\section{Statistical analyses}

The Fisher test or Chi-2 test was used for comparison of all patients according to viral results and clinical data in inpatients and outpatient's groups. The logistic-regression model was used to examine association of virus detection with sex, age group and clinical data. A P value < 0.05 was considered statistically significant. The R software (R.3.0.1 version) was used to perform the statistical analyses.

\section{Ethical management}

This protocol was approved as less than minimal risk research by the Ministry of Health in its guidelines for influenza surveillance policy. The protocol and oral consent were determined as routine surveillance activity by the Senegalese National Ethics committee and the steering committee for $4 \mathrm{~S}$ network [8], an entity representing $\mathrm{MoH}$, IPD, WHO and Clinicians in compliance with all applicable National regulations governing the protection of human subjects. Data were collected anonymously in an objective of surveillance and applicable to a molecular epidemiology studies on the detected pathogen. The information provided to participants was an informal description of the study. Respiratory specimens were collected, only after informed consent was granted, verbally, to local health care workers by the parents or tutors of children. Oral consent was documented in the patient form with two questions about received information and about oral consent. For the surveillance activities, written consent is judged not necessary by the Senegalese national ethics committee, which has also previously approved the work of the National Influenza Center. Collections of non-sensitive data or an observation from normal care in which participants remain anonymous do not require ethics committee review. The patients included in this study were consulted the health care centers due to influenza-like symptoms; parents accept the sampling and the tests for respiratory viruses largely because they are free and safe.

\section{Results}

\section{Demographic and clinical characteristics of children}

From May 2014 to December 2015, nasopharyngeal swabs were collected from 288 children with ARI whose age varied from 0 up to 5 years (Table 1): 164 (56.9\%) were from Roi Baudouin Hospital, 74 (25.7\%) from Abass Ndao Hospital and 50 (17.4\%) were from Aristide Ledantec Hospital. Of these children, 93 (32.3\%) required hospitalization.

The ages of the children ranged from 3 days to 5 years, with a mean age of 25.5 months and a median age of 18 months. The male to female ratio was 1.54 (173 [60.8\%] males and 112 [39.2\%] females). Sex information was not available in 3 cases. The most common age group was infants with age $>24$ months, $42 \%$ (121/288). Children of age group 12-24 months represented $23.3 \%$ (67/288), while children of age groups 0-6 and 6-12 months represented $16.3 \%$ (47/288) and 18.4 $\%$ (53/288), respectively.

Regarding clinical symptoms the majority of children presented at admission suffered from fever $(74.6 \% ; 215 / 288)$, cough $(62.1 \%$; $179 / 288)$, and rhinorrhea $(39.9 \% ; 115 / 288)$. Dyspnea $(21.2 \% ; 61 / 288)$, sore throat $(9.4 \% ; 27 / 288)$ and tachypnea $(9 \% ; 26 / 288)$ were also reported. We also noted that dyspnea $(73.8 \%, 45 / 61)$, tachypnea $(84.6 \% ; 22 / 26)$, pulmonary condensation $(90 \%, 9 / 10)$ and weight loss $(60 \%, 6 / 10)$ were closely linked to hospitalization.

Clinically, rhinitis (33\%; 95/288), bronchitis (39.2\%; 113/288), bronchiolitis $(17.4 \% ; 50 / 288)$, tonsillitis $(14.6 \% ; 42 / 288)$ and pneumonia (7.3\%;21/288) were the most common diagnostic. Otitis $(4.2 \% ; 12 / 288)$ and pharyngitis $(3.1 \%$; $9 / 288)$ were also found. Pneumonia $(19 / 21 ; \mathrm{p}<$ $0.0001)$, bronchiolitis $(22 / 50 ; \mathrm{p}<0.001)$, acute bronchitis $(26 / 113 ; \mathrm{p}=$ 
Table 1. Demographic characteristics, symptoms and diagnosis.

\begin{tabular}{|c|c|c|c|c|}
\hline & Inpatients( $\mathrm{N}=93)$ & Outpatients(N=195) & Total $(\mathrm{N}=\mathbf{2 8 8})$ & p Value \\
\hline \multicolumn{5}{|c|}{ Gender } \\
\hline Male & $55(59.1)$ & $118(61.5)$ & $173(60.8)$ & - \\
\hline Female & $38(40.9)$ & $74(38.5)$ & $112(39.2)$ & 0.697 \\
\hline \multicolumn{5}{|c|}{ Group Age (months) } \\
\hline$[0-6]$ & $20(21.5)$ & $27(13.9)$ & $47(19.4)$ & 0.3090 \\
\hline ]6-12] & $17(18.3)$ & $36(18.6)$ & $53(18.5)$ & 0.2800 \\
\hline ]12-24] & $23(24.8)$ & $44(22.2)$ & $67(23.0)$ & 0.3732 \\
\hline $24+$ & $33(35.5)$ & $88(45.4)$ & $121(42.2)$ & 0.0578 \\
\hline \multicolumn{5}{|c|}{ Clinical signs } \\
\hline Cough & $64(68.8)$ & $115(59.0)$ & $179(62.2)$ & 0.1199 \\
\hline Dyspnea & $45(48.4)$ & $16(8.2)$ & $61(21.2)$ & $4.338 \mathrm{e}-14$ \\
\hline Sore throat & $9(9.7)$ & $18(9.2)$ & $27(9.4)$ & 0.903 \\
\hline Fever & $73(78.5)$ & $142(72.8)$ & $215(74.7)$ & 0.3152 \\
\hline Tachypnea & $22(23.7)$ & $4(2.1)$ & $26(9.0)$ & $1.107 \mathrm{e}-08$ \\
\hline Weight loss & $6(6.5)$ & $4(2.1)$ & $10(3.5)$ & 0.0817 \\
\hline Otorrhoea & $3(3.2)$ & $2(1.0)$ & $5(1.7)$ & 0.3328 \\
\hline $\begin{array}{l}\text { Pulmonary } \\
\text { condensation }\end{array}$ & $9(9.7)$ & $1(0.5)$ & $10(3.5)$ & 0.0002 \\
\hline Rhinorrhea & $39(41.9)$ & $76(39.0)$ & $115(39.9)$ & 0.6997 \\
\hline \multicolumn{5}{|c|}{ Diagnosis } \\
\hline Pneumonia & $19(20.4)$ & $2(0.7)$ & $21(7.3)$ & $1.373 \mathrm{e}-08$ \\
\hline $\begin{array}{c}\text { Acute } \\
\text { bronchitis }\end{array}$ & $26(28.0)$ & $87(29.5)$ & $113(39.2)$ & 0.0069 \\
\hline Bronchiolitis & $22(23.7)$ & $28(9.5)$ & $50(17.4)$ & 0.0665 \\
\hline Acute otitis & $4(4.3)$ & $8(2.7)$ & $12(4.2)$ & 0.937 \\
\hline Rhinitis & $18(19.4)$ & $77(29.1)$ & $95(33.0)$ & 0.0007 \\
\hline Tonsillitis & $12(12.9)$ & $30(10.2)$ & $42(14.6)$ & 0.7213 \\
\hline Pharyngitis & $4(4.3)$ & $5(1.7)$ & $9(3.1)$ & 0.4766 \\
\hline $\begin{array}{l}\text { Acute } \\
\text { sinusitis }\end{array}$ & $1(1.1)$ & $0(0.0)$ & $1(0.3)$ & 0.3229 \\
\hline Meningitis & $2(2.2)$ & $0(0.0)$ & $2(0.7)$ & 0.1035 \\
\hline Tracheitis & $2(2.2)$ & $1(0.3)$ & $3(1.0)$ & 0.2447 \\
\hline
\end{tabular}

$0.006)$ and tonsillitis $(12 / 42 ; \mathrm{p}<0.001)$ were significantly associated with hospitalization. All cases of tracheitis (3), meningitis (2) and acute sinusitis (1) were also hospitalized.

\section{Patients and viral detection}

Viral etiologies were identified in the vast majority $(77.8 \%, 224 / 288)$ of patients while $64(22.2 \%)$ were negative for all viruses tested. Single viral infections accounted for $30.5 \%$ (88/288) of cases and co-infections with multiple viruses were found in $46.9 \%$ (135/288), mainly with the association of HAdV or influenza viruses (Table 2). In 56 samples (19.4 $\%)$ more than two viruses were detected.

A total of 439 respiratory viruses were identified in all children. Among these, 254 (57.8\%) were detected in hospitalized children. Adenoviruses $(44.4 \% ; 128 / 288)$, influenza viruses $(37.5 \% ; 108 / 288)$ and rhinoviruses $(28.5 \% ; 82 / 288)$ were the most frequently detected among the children (Table 3). We also detected human enteroviruses (HEV) in 57 children (19.8\%) and human respiratory syncytial virus (RSV) in 29 children (10.1\%). Other viruses have been detected below $5 \%$ rate: human bocavirus $(4.5 \% ; 13 / 288)$, parainfluenza viruses $(3.1 \% ; 9 / 288)$, human coronaviruses $(2.4 \% ; 7 / 288)$ and human metapneumoviruses (2.1\%; 6/288). Regarding mono-infection criterion, rates are proportional to the virus whole detection rates. Indeed, adenoviruses are the most frequently detected in single infection with 31 cases (24.2\%; 31/128) followed by influenza viruses $(24.8 \%$; $26 / 105)$, HRV (19.5\%; 16/82) and HEV with 9 cases $(15.8 \%$; 9/57). RSV and HBoV are detected respectively three and two times in single infection. HRV mono-infections are associated to hospitalization in $92.3 \%(12 / 13)$, a significantly higher percentage than other viruses $(\mathrm{P}<0.01)$, followed by influenza virus $(57.1 \% ; 8 / 14)$. RSV infections occurred at a younger age than other viral infections, and were significantly more frequent in the first 6 months of life (Fisher exact test p-value $=0.0213$ ). In contrast, none of the other viruses exhibited significant age group distribution differences.

Taking into account the clinical diagnosis and detected viruses, RSV and HRV are the most associated viruses with bronchiolitis disease (24.1\% and $15.8 \%$ respectively), HMPV detection was mostly associated with acute bronchitis $(50 \%)$ and $\mathrm{HCoV}$ with rhinitis (Table $3)$. These different associations were not statistically significant $(P>$ $0.05)$. Any significant association $(\mathrm{P}>0.05)$ was also observed between a virus detection and a clinical symptom.

No significance difference was observed in the distribution of the viral detection rate of the viruses according to the age group. However, we noticed a detection ratio of 1.8 viruses per patient in children less than 6 months, which represented a high ratio as compared to other groups.

\section{Discussion}

This is the first study in Senegal that investigated the role of 16 different respiratory viruses in children with ARI using sensitive molecular methods over a 2-year period. Our data support the conclusion that respiratory viruses are significantly involved in childhood acute respiratory infections in Senegal. Interestingly, this study in line with previous reports suggests that acute respiratory infections are a major public health issue in children worldwide [2]. Therefore, these findings could be very useful for public health policies in our country and in the sub-Saharan region.

Indeed, we showed that 224 samples from the children with ARI out of 288 contained at least one of the targeted respiratory viruses. All targeted viruses have been detected in at least one patient.

The frequency of virus detection (77.8\%) among the children with ARI in our study is high compared with those found in several other studies from other countries. For example Kaplan, et al. [17], in a similar study conducted in Jordan detected at least one respiratory virus in $75.5 \%$ of the children, Kenmoe, et al. [18], in Cameroon detected at least one respiratory virus in $65.4 \%$ of the children, Amer, et al. [19] in Saudi Arabia had a detection rate of $60.3 \%$, Lee, et al. [20] in Taiwan 60.2\%, Wertheim, et al. [21] 58.6\% (in patients from Thailand, Vietnam and Indonesia), Lu, et al. [22] in China 55.8\%, Giamberardin, et al. [23] in Brazil 55\% or Khamis, et al. [24] in Oman with $50 \%$. Even lower detection rates were obtained in studies performed in Europe or the USA: Moe, et al. [25] in Norway (43\%), Pierangeli, et al. [26] in Italy (42.7\%) or Wansaula, et al. [27] in USA (43.3\%). However, higher rates than ours were observed in a study conducted by Do, et al. [28] in children less than 2 years old in Vietnam (91\%) and another one in Cyprus (85.8\%) by Richter, et al. [29]. However, it should be noted that the technical approaches used could at least partly explain the discrepancies in viral detection rates: primarily in their sensitivity differences and secondly in the number of targeted viruses. Alternatively differences in rates of detection could be due to true geographical differences in overall burden, differences in study populations (outpatients or hospitalized patients), ARI case definition differences and to the studies sample collection periods.

Of the 439 viruses detected in the children, adenovirus was the most common viral pathogen with $44.4 \%$ of the total number of detected viruses. This result is consistent with the data collected since 
Table 2. Viral co-detections in children less than 5 years old with acute respiratory infections in Senegal.

\begin{tabular}{|c|c|c|c|c|c|c|c|c|}
\hline Virus types & HAdV & PIV & FLU & HRV & HMPV & HBoV & HCoV & RSV \\
\hline HAdV & $128(100)$ & & & & & \\
\hline PIV & $4(3.1)$ & $9(100)$ & & & & \\
\hline FLU & $59(46.1)$ & $5(55.6)$ & $108(100)$ & & & \\
\hline HRV & $44(34.4)$ & $4(44.4)$ & $31(28.7)$ & $82(100)$ & & \\
\hline HMPV & $3(2.3)$ & $0(0.0)$ & $3(2.8)$ & $0(0.0)$ & $6(100)$ & \\
\hline HBoV & $6(4.7)$ & $0(0.0)$ & $6(5.6)$ & $7(8.5)$ & $1(16.7)$ & $13(100)$ & \\
\hline HCoV & $5(3.9)$ & $0(0.0)$ & $2(1.9)$ & $4(4.9)$ & $0(0.0)$ & $0(0.0)$ & \\
\hline RSV & $15(11.7)$ & $0(0.0)$ & $14(13)$ & $16(19.5)$ & $1(16.7)$ & $1(7.7)$ & $0(100)$ \\
\hline HEV & $26(20.3)$ & $3(33.3)$ & $24(22.2)$ & $21(25.6)$ & $2(33.3)$ & $5(38.5)$ & \\
\hline Single detection & $31(24.2)$ & $0(0)$ & $26(24.1)$ & $16(19.5)$ & $1(16.7)$ & $2(15.4)$ & \\
\hline & & & & & \\
\hline
\end{tabular}

Table 3. Clinical characteristic of acute respiratory infection and viral detection in children less than 5 years old in Senegal.

\begin{tabular}{|c|c|c|c|c|c|c|c|c|c|}
\hline & HAdV & PIV & FLU & HRV & HMPV & HBoV & $\mathrm{HCoV}$ & RSV & HEV \\
\hline & N (\%) & $\mathrm{N}(\%)$ & N (\%) & N (\%) & $\mathrm{N}(\%)$ & N (\%) & N (\%) & $\mathrm{N}(\%)$ & $\mathrm{N}(\%)$ \\
\hline Detection & $128(44.4)$ & $9(3.1)$ & $105(36.5)$ & $82(28.5)$ & $6(2.1)$ & $13(4.5)$ & $7(2.4)$ & $29(10.1)$ & $57(19.8)$ \\
\hline Hospitalized & $43(33.6)$ & $4(44.4)$ & $38(35.2)$ & $30(36.6)$ & $2(33.3)$ & $3(23.1)$ & $2(28.6)$ & $12(41.4)$ & $20(35.1)$ \\
\hline \multicolumn{10}{|c|}{ Gender } \\
\hline Male & $76(53.4)$ & $6(66.7)$ & $67(62.0)$ & $55(67.1)$ & $3(50.0)$ & $9(69.2)$ & $5(71.4)$ & $19(65.5)$ & $35(61.4)$ \\
\hline Female & $52(40.6)$ & $3(33.3)$ & $41(38.0)$ & $27(32.9)$ & $3(50.0)$ & $4(30.8)$ & $2(28.6)$ & $10(34.5)$ & $22(38.6)$ \\
\hline \multicolumn{10}{|c|}{ Diagnosis } \\
\hline Pneumonia & $14(10.3)$ & $1(11.1)$ & $10(9.3)$ & $6(7.3)$ & $(0.0)$ & $2(15.4)$ & $(0.3)$ & $3(10.3)$ & $4(7.0)$ \\
\hline Acute bronchitis & $48(37.5)$ & $6(66.7)$ & $37(34.3)$ & $29(35.4)$ & $3(50.0)$ & $6(46.2)$ & $3(42.5)$ & $8(27.6)$ & $24(42.1)$ \\
\hline Bronchiolitis & $21(16.4)$ & $(0.0)$ & $11(10.2)$ & $14(17.1)$ & $(0.0)$ & $1(7.7)$ & $1(14.4)$ & $7(24.1)$ & $6(10.5)$ \\
\hline Acute otitis & $6(4.7)$ & $1(11.1)$ & $8(7.4)$ & $5(6.1)$ & $(0.0)$ & $(0.0)$ & $1(14.7)$ & $2(6.9)$ & $1(1.8)$ \\
\hline Rhinitis & $43(33.6)$ & $3(33.3)$ & $42(38.9)$ & $28(34.1)$ & $1(16.6)$ & $1(7.7)$ & $4(57.6)$ & $10(34.5)$ & $23(40.4)$ \\
\hline Tonsillitis & $19(14.8)$ & $(0.0)$ & 21(19.4) & $13(15.9)$ & $(0.0)$ & $2(15.4)$ & $1(14.8)$ & $1(3.4)$ & $8(14.0)$ \\
\hline \multicolumn{10}{|c|}{ sign clinical } \\
\hline Cough & $84(65.6)$ & $7(77.8)$ & $63(58.3)$ & $50(61.0)$ & $5(83.3)$ & $6(46.2)$ & $3(42.6)$ & $18(62.1)$ & $34(59.6)$ \\
\hline Dyspnea & $30(23.4)$ & $2(22.2)$ & $22(20.4)$ & $20(24.4)$ & $1(16.6)$ & $2(15.4)$ & $1(14.4)$ & $7(24.1)$ & $10(17.5)$ \\
\hline Sore throat & $12(3.4)$ & $1(11.1)$ & $11(10.2)$ & $14(17.1)$ & $(0.0)$ & $1(7.7)$ & $2(28.4)$ & $1(3.4)$ & $6(10.5)$ \\
\hline Weight loss & $7(5.5)$ & $2(22.2)$ & $4(3.7)$ & $2(2.4)$ & $(0.0)$ & $1(7.7)$ & $(0.5)$ & $(0.0)$ & $5(8.8)$ \\
\hline Fever & $93(72.7)$ & $7(77.8)$ & $80(74.1)$ & $59(72.0)$ & $5(83.3)$ & $11(84.6)$ & $3(42.7)$ & $24(82.8)$ & $42(73.7)$ \\
\hline Tachypnea & $15(11.7)$ & $1(11.1)$ & $10(9.3)$ & $5(6.1)$ & $(0.0)$ & $(0.0)$ & $(0.7)$ & $4(13.8)$ & $5(8.8)$ \\
\hline Otorrhoea & $2(1.6)$ & $(0.0)$ & $4(3.7)$ & $1(1.2)$ & $(0.0)$ & $(0.0)$ & $(0.6)$ & $1(3.4)$ & $1(1.8)$ \\
\hline $\begin{array}{l}\text { Condensation } \\
\text { pulmonary }\end{array}$ & $7(5.5)$ & 1(11.1) & $5(4.6)$ & $3(3.7)$ & $(0.0)$ & $(0.0)$ & $(0.5)$ & $3(10.3)$ & $3(5.3)$ \\
\hline Rhinorrhea & $53(41.4)$ & $5(55.6)$ & $45(41.7)$ & $42(51.2)$ & $3(50.0)$ & $6(46.2)$ & $5(71.4)$ & $20(69.0)$ & $28(49.1)$ \\
\hline \multicolumn{10}{|c|}{ Age groups/Viral detection } \\
\hline$[0-6]$ months & $22(46.8)$ & $1(2.1)$ & $17(36.2)$ & $20(42.6)$ & $1(2.1)$ & $1(2.1)$ & $2(4.3)$ & $10(21.3)$ & $10(21.3)$ \\
\hline ]6-12] months & $24(45.3)$ & $2(3.8)$ & $14(26.4)$ & $15(28.3)$ & $2(3.8)$ & $(0.0)$ & $1(1.9)$ & $7(13.2)$ & $13(24.5)$ \\
\hline ]12-24] months & $30(44.8)$ & $1(1.5)$ & $27(40.3)$ & $14(20.9)$ & $1(1.5)$ & $6(9.0)$ & $1(1.5)$ & $3(4.5)$ & 13(19.4) \\
\hline$<24$ months & $52(43.0)$ & $5(4.1)$ & $47(38.8)$ & $33(27.3)$ & $2(1.7)$ & $6(5.0)$ & $3(2.5)$ & $9(7.4)$ & 21(17.4) \\
\hline p-Value & 0.9759 & 0.7553 & 0.2218 & 0.1241 & 0.3935 & 0.1808 & 0.8985 & 0.04677 & 0.7103 \\
\hline
\end{tabular}

2012 from our sentinel surveillance of other respiratory viruses in people with influenza-like illnesses in Senegal [8]. Indeed we observed a strong activity of adenoviruses in Senegal throughout the year (data not shown). Adenoviruses were observed in the same proportions $(27.3 \%)$ in a similar study in Cameroon [18]. The detection rates found in Senegal and Cameroon are considerably higher than those found in other geographical areas: Nascimento-Carvalho, et al. [30] in Brazil with 3\%, Moe, et al. [25] (2016) in Norway (1.7\%), Wansaula, et al. [27] in USA (1\%) or Lu, et al. [22] in China. These results suggest a strong association of adenoviruses in human respiratory tract in African populations even if disease causation has not convincingly been proven. In fact, the presence of a virus in the nasopharynx of a child does not necessarily mean that it is the etiological agent of the ILI or ARI. Therefore, it may only represent a coincidental upper airway infection, an asymptomatic carrier state, or prolonged shedding of a pathogen that caused a previous infection. For adenoviruses, additional investigations (epidemiology, circulating genotypes...) will help to assess the real importance of this virus in respiratory infection diseases.

Influenza viruses were detected in $36.5 \%$ of patients, which highlights the importance of these viruses in the genesis of local respiratory infections among children in Senegal. This rate is relatively high compared to those obtained in several other studies $[4,18,27,31,32]$ even if others studies had concluded that influenza viruses are more likely to be detected in under 5-year-old patients, with an incidence of 9.4-9.6\% in the last 2 years [33-35]. Moreover, Van Woensel, et al. [36] argued that infants and young children have a 12-fold increased risk of admission to hospital for respiratory tract infection caused by influenza virus compared with children aged 5-17 years. In any case, our results clearly support that children under 5 years of age are a highrisk group of complications regarding influenza virus's infection and the prospect 
of implementing seasonal influenza vaccination in this age group in Senegal becomes a real public health necessity.

Picornaviruses (Rhinovirus and Enterovirus) accounted for about $48.3 \%$ of viral infections in our population. This high circulation of picornaviruses in children was clearly reflected in the data collected after many years of surveillance of these viruses in people in Senegal [9]. Interestingly, in the present pediatric study about $59.7 \%$ of picornaviruses infection cases are related to low respiratory tract infections (LRTIs) although these viruses are usually related to mild URTI. These results underline a need for picornaviruses investigation during viral diagnosis of respiratory tract diseases in light of recently published data regarding the association of rhinoviruses especially with severe respiratory tract infections in children [37-39], and in asthma exacerbations [16,40-42].

Regarding RSV, our results are lower than the rates reported in several other similar studies. Among many examples we can cite the studies carried out in other low and middle-income countries including Bangladesh [43], Kenya [44], Mozambique, South Africa [45] El Salvador [46], Costa Rica [47], in Jordan [17], in Vietnam [29] and Thailand [48]. Otherwise, the proportion in Senegal (10.1\%) was similar to that reported in Cameroon [18], in Mozambique [49] or Nepal [50]. However, as shown in our study, it is globally well documented that RSV represents a substantial burden of acute respiratory tract illness particularly in the early years of life (especially in the first six months), leading to severe morbidity and hospitalization in very young children $[43,51,52]$. Therefore, in a World Health Organization (WHO) vaccine perspective against this virus, the importance of long-term molecular epidemiological surveys for early detection of prevalent strains and newly emerging genotypes cannot be over emphasized to foster better understanding of RSV infections in Senegal. In future study, for a better assessment of the RSV burden among children in Senegal focusing on pediatric hospitalized cases, data on disease outcome, atypical clinical signs, duration of symptoms, duration of hospitalization and treatment should be collected.

The remaining viral etiologies were identified below 5\%: bocaviruses $4.5 \%$, parainfluenza with $3.1 \%$, human coronaviruses $2.4 \%$ and human metapneumovirus with $2.1 \%$. These low circulation rates are in line with those reported in many other similar studies [18,23,24,26,29].

Mixed infections were observed in approximately $46.9 \%$ of all samples, which is much higher than those previously reported rates ranging from $4.8 \%$ in Italy [27] to $29.5 \%$ in Cameroon [18]. EV, RSV, $\mathrm{HBoV}$, and $\mathrm{HCoV}$ were found most frequently in co-infections. Even though this study did not allow for investigating a possible association between multiple infections and disease severity, literary data show that such a potential association is still controversial.

Our study did have several limitations. The first weakness is the small number of samples collected in this study. An increase number of samples, along with the participation of more hospital sites will be critical to complete the picture for both the targeted viruses and the clinical diagnoses in children with ARI in Senegal. It will also be interesting to extend the recruitment period of the study as it would make possible to assess the seasonality of the infections. The lack of matched control groups is another limitation of the study especially to appreciate the asymptomatic viral carriage which will help to investigate a clinical causal link. In future work, it will be critical to compare the bacterial and viral etiologies, and also to study the clinical value of virus/bacteria co-infections in children with ARI. The role of bacteria as a cause of LRTI or as cause of super infection is well known, especially in RSV and influenza virus infection [53]. Bacteria investigation is also important for antibiotic intervention strategies. However, bacteria diagnostic is not easy as lower airway secretions (like sputum) considered as the optimal specimen type for detecting bacterial (co-) infection, are often difficult to obtain from young children, and can only be readily obtained from intubated children.

\section{Conclusion}

In summary, our study provides novel insights into the epidemiology and clinical impact of respiratory viruses among children under 5 years old, the most vulnerable age group, in a lowincome West African country, Senegal. It highlights a high diversity and prevalence of respiratory viruses circulating in this age group. It arises from these results a need for implementation of surveillance programs for respiratory viral infections in order to collect exhaustive data for crucial analyses (seasonality, targeted group ages, causal roles of viral pathogens and the risk factors that may correlate with more severe disease ...) seeking to guide preventive public health measures.

\section{Authors' contributions}

The work presented here was carried out in collaboration between all authors. $N D, M N, C S B$, and $O N$ defined the research, analyzed and interpreted the data, and revised the manuscript; $A F$ and $A D 1$ performed and coordinated technical work; $N D, A F, S F W$ and $M N N$ wrote the draft and revisions of the paper; $A D 2, J B N D, D B, Y K$ and $A S$ contributed in the samples and data collection. All authors contributed to, seen and approved the manuscript.

\section{Acknowledgments}

This study would not have been possible without the excellent support from all the health-care workers of Abass Ndao, Aristide Ledantec and Roi Baudoin pediatric healthcare. We convey our special thanks to Kathleen Victoir from the International Network of Pasteur Institutes for her unwavering support to the Senegalese National Influenza Center. We acknowledge the Senegalese ministry of health for their help in implementing the 4S Network.

\section{Funding information}

This work was supported by the Department of Health and Human Service (DHSS) via the International Network of Pasteur Institutes and Pasteur Institute of Dakar.

\section{Competing interests}

The authors have no competing interests.

\section{References}

1. Scheltinga SA, Templeton KE, Beersma MF, Claas EC (2005) Diagnosis of human metapneumovirus and rhinovirus in patients with respiratory tract infections by an internally controlled multiplex real-time RNA PCR. J Clin Virol 33: 306-311.

2. Grassi T, Mancini F, Ciervo A, Vescio MF, Ghazal A, et al. (2014) Chlamydophila pneumoniae, Mycoplasma pneumoniae, and influenza in children with respiratory infections in Alexandria, Egypt. 2014. J Infect Dev Ctries 8: 379-383.

3. Nair GB, Niederman MS (2013) Year in review 2012: Critical Care--respiratory infections. Crit Care 17: 251. [Crossref]

4. Liu T, Li Z, Zhang S, Song S, Julong W, et al. (2015) Viral Etiology of acute respiratory tract infections in hospitalized children and adults in Shandong Province, China. Virol $J 12: 168$.

5. Williams BG1, Gouws E, Boschi-Pinto C, Bryce J, Dye C (2002) Estimates of worldwide distribution of child deaths from acute respiratory infections. Lancet Infect Dis 2 . 25-32. [Crossref] 
6. Luksic I, Kearns PK, Scott F, Rudan I, Campbell H, et al. (2013) Viral etiology of hospitalized acute lower respiratory infections in children under 5 years of age - a systematic review and meta-analysis. 2013. Croat Med J 54: 122-134.

7. Karaivanova GM (1995) Viral respiratory infections and their role as publichealth problem in tropical countries (review). Afr J Med Med Sci 24: 1-7.

8. Dia N, Diene Sarr F, Thiam D, Faye Sarr T, Espié E, et al. (2014) Influenza-like illnesses in Senegal: not only focus on influenza viruses. PLoS One 9: e93227.

9. Fall A, Dia N, Kébé O, Sarr FD, Kiori DE, et al. (2016) Enteroviruses and Rhinoviruses: Molecular Epidemiology of the Most Influenza-Like Illness Associated Viruses in Senegal. Am J Trop Med Hyg 95: 339-347.

10. Fall A, Dia N, Cisse el HA, Kiori DE, Sarr FD, et al. (2016) Epidemiology and Molecular Characterization of Human Respiratory Syncytial Virus in Senegal after Four Consecutive Years of Surveillance, 2012-2015. PLoS One 11: e0157163.

11. Mejias A, Chavez-Bueno S, Jafri HS, Ramilo O (2005) Respiratory syncytial virus infections: old challenges and new opportunities. 2005. Pediatr Infect Dis J 24: S189-196.

12. McIntyre CL, Knowles NJ, Simmonds P (2013) Proposals for the classification of human rhinovirus species A, B and C into genotypically assigned types. J Gen Virol 94:1791-1806.

13. Jackson DJ, Gangnon RE, Evans MD, Roberg KA, Anderson EL, et al. (2008) Wheezing rhinovirus illnesses in early life predict asthma development in high-risk children. Am J Respir Crit Care Med 178: 667-672.

14. de Almeida MB, Zerbinati RM, Tateno AF, Oliveira CM, Romão RM, et al. (2010) Rhinovirus $\mathrm{C}$ and respiratory exacerbations in children with cystic fibrosis. Emerg Infect Dis 16: 996-999.

15. Seemungal TA, Harper-Owen R, Bhowmik A, Jeffries DJ, Wedzicha JA (2000) Detection of rhinovirus in induced sputum at exacerbation of chronic obstructive pulmonary disease. Eur Respir J 16: 677-683. [Crossref]

16. Piotrowska Z, Vázquez M, Shapiro ED, Weibel C, Ferguson D, et al. (2009) Rhinoviruses are a major cause of wheezing and hospitalization in children less than 2 years of age. Pediatr Infect Dis $J$ 1: 25-29.

17. Kaplan NM, Dove W, Abd-Eldayem SA, Abu-Zeid AF, Shamoon HE, et al. (2008) Molecular epidemiology and disease severity of respiratory syncytial virus in relation to other potential pathogens in children hospitalized with acute respiratory infection in Jordan. J Med Virol 80: 168-174.

18. Kenmoe S, Tchendjou P, Vernet MA, Moyo-Tetang S, Mossus T, et al (2016) Vira etiology of severe acute respiratory infections in hospitalized children in Cameroon, 2011-2013. 2016. Influenza Other Respir Viruses 10: 386-393.

19. Amer HM, Alshaman MS, Farrag MA, Hamad ME, Alsaadi MM, et al. (2016) Epidemiology of 11 respiratory RNA viruses in a cohort of hospitalized children in Riyadh, Saudi Arabia. J Med Virol 88: 1086-1091.

20. Lee CY, Chang YF, Lee CL, Wu MC, Ho CL, et al. (2015) Molecular viral epidemiology and clinical characterization of acute febrile respiratory infections in hospitalized children in Taiwan. J Med Virol 87: 1860-1866.

21. Wertheim HF, Nadjm B, Thomas S, Agustiningsih A, Malik S, et al. (2015) Viral and atypical bacterial aetiologies of infection in hospitalised patients admitted with clinical suspicion of influenza in Thailand, Vietnam and Indonesia. Influenza Other Respir Viruses 6: 315-322.

22. Lu Y, Wang S, Zhang L, Xu C, Bian C, et al. (2013) Epidemiology of human respiratory viruses in children with acute respiratory tract infections in Jinan, China. Clin Dev Immunol 2013: 210490 .

23. Giamberardin HI, Homsani S, Bricks LF, Pacheco AP, Guedes M, et al. (2016) Clinical and epidemiological features of respiratory virus infections in preschool children over two consecutive influenza seasons in southern Brazil. J Med Virol 8: 1325-1333.

24. Khamis FA, Al-Kobaisi MF, Al-Areimi WS, Al-Kindi H, Al-Zakwani I (2012) Epidemiology of respiratory virus infections among infants and young children admitted to hospital in Oman. J Med Virol 84: 1323-1329.

25. Moe N, Pedersen B, Nordbø SA, Skanke LH, Krokstad S, et al. (2016) Respiratory Virus Detection and Clinical Diagnosis in Children Attending Day Care. PLoS One 11: e0159196.

26. Pierangeli A, Gentile M, Di Marco P, Pagnotti P, Scagnolari C, et al. (2007) Detection and typing by molecular techniques of respiratory viruses in children hospitalized for acute respiratory infection in Rome, Italy. J Med Virol 79: 463-468.

27. Wansaula Z, Olsen SJ, Casal MG, Golenko C, Erhart LM, et al. (2016) Surveillance for severe acute respiratory infections in Southern Arizona, 2010-2014. Influenza Other Respir Viruses 10: 161-169.
28. Do LA, Bryant JE, Tran AT, Nguyen BH, Tran TT, et al. (2016) Respiratory Syncytial Virus and Other Viral Infections among Children under Two Years Old in Southern Vietnam 2009-2010: Clinical Characteristics and Disease Severity. PLoS One 11: e0160606.

29. Richter J, Panayiotou C, Tryfonos C, Koptides D, Koliou M, et al. (2016) Aetiology of Acute Respiratory Tract Infections in Hospitalised Children in Cyprus. PLoS One 11: $\mathrm{e} 0147041$

30. Nascimento-Carvalho CM, Ribeiro CT, Cardoso MRA (2008) The role of respiratory viral infections among children hospitalized for community-acquired pneumonia in a developing country. Pediatr Infect Dis J 27: 939-941.

31. Khadadah M, Essa S, Higazi Z, Behbehani N, Al-Nakib W (2010) Respiratory syncytial virus and human rhinoviruses are the major causes of severe lower respiratory tract infections in Kuwait. J Med Virol 82: 1462-1467.

32. Wang H, Zheng Y, Deng J, Wang W, Liu P, et al. (2016) Prevalence of respiratory viruses among children hospitalized from respiratory infections in Shenzhen, China Virol J 13: 39.

33. Watanabe AS, Carraro E, Moreira L, Camargo C, Sinohara J, et al. (2009) Respiratory virus infections among hospitalized patients with suspected influenza A H1N1 2009 virus during the first pandemic wave in Brazil. Braz J Infect Dis 15: 220-224.

34. Turner P, Turner C, Watthanaworawit W, Carrara V, Cicelia N, et al. (2013) Respiratory virus surveillance in hospitalised pneumonia patients on the Thailand-Myanmar border. BMC Infect Dis 13: 434.

35. Kwon JM, Shim JW, Kim DS, Jung HL, Park MS, et al. (2014) Prevalence of respiratory viral infection in children hospitalized for acute lower respiratory tract diseases, and association of rhinovirus and influenza virus with asthma exacerbations. Korean $J$ Pediatr 57: 29-34

36. van Woensel JB, van Aalderen WM, Kimpen JL (2003) Viral lower respiratory tract infection in infants and young children. BMJ 327: 36-40.

37. Iwane MK, Prill MM, Lu X, Miller EK, Edwards KM, et al. (2011) Human rhinovirus species associated with hospitalizations for acute respiratory illness in young US children. J Infect Dis 204: 1702-1710.

38. Fuji N, Suzuki A, Lupisan S, Sombrero L, Galang H, et al. (2011) Detection of human rhinovirus $\mathrm{C}$ viral genome in blood among children with severe respiratory infections in the Philippines. PLoS One 6: e27247.

39. Lauinger IL, Bible JM, Halligan EP, Bangalore H, Tosas O, et al. (2013) Patien characteristics and severity of human rhinovirus infections in children. J Clin Virol 58 : 216-220. [Crossref]

40. Kotaniemi-Syrjänen A, Vainionpää R, Reijonen TM, Waris M, Korhonen K, et al (2003) Rhinovirus-induced wheezing in infancy--the first sign of childhood asthma? $J$ Allergy Clin Immunol 111: 66-71. [Crossref]

41. Miller EK, Edwards KM, Weinberg GA, Iwane MK, Griffin MR, et al. (2009) A novel group of rhinoviruses is associated with asthma hospitalizations. J Allergy Clin Immunol 123: 98-104. [Crossref]

42. Bizzintino J, Lee WM, Laing IA, Vang F, Pappas T, et al. (2011) Association between human rhinovirus $\mathrm{C}$ and severity of acute asthma in children. Eur Respir J 37: 10371042. [Crossref]

43. Homaira N, Luby SP, Hossain K, Islam K, Ahmed M, Rahman M, et al (2016) Respiratory Viruses Associated Hospitalization among Children Aged $<5$ Years in Bangladesh: 2010-2014. PLoS One 11: e0147982.

44. Feikin DR, Ope MO, Aura B, Fuller JA, Gikunju S, et al. (2012) The population-based burden of influenza-associated hospitalization in rural western Kenya, 2007-2009. Bull World Health Organ 90: 256-63A.

45. Robertson SE, Roca A, Alonso P, Simoes EA, Kartasasmita CB, et al. (2004) Respiratory syncytial virus infection: denominator-based studies in Indonesia, Mozambique, Nigeria and South Africa. Bull World Health Organ 82: 914-922.

46. Clara W, Armero J, Rodriguez D, de Lozano C, Bonilla L, et al. (2012) Estimated incidence of influenza-virus-associated severe pneumonia in children in El Salvador, 2008-2010. Bull World Health Organ 90: 756-763.

47. Saborio GG, Clara A, Garcia A, Quesada F, Palekar R, et al. (2014) Influenza-associated Hospitalizations and Deaths, Costa Rica, 2009-2012. Emerg Infect Dis 20: 878-881.

48. Fry AM, Chittaganpitch M, Baggett HC, Peret TC, Dare RK, et al. (2010) The burden of hospitalized lower respiratory tract infection due to respiratory syncytial virus in rural Thailand. PLoS One 5: e15098.

49. O'Callaghan-Gordo C, Bassat Q, Morais L, Díez-Padrisa N, Machevo S, et al. (2011) Etiology and epidemiology of viral pneumonia among hospitalized children in rura Mozambique: a malaria endemic area with high prevalence of human immunodeficiency virus. Pediatr Infect Dis J 30: 39-44. 
Fall A (2017) Children under five years of age in senegal: A group highly exposed to respiratory viruses infections

50. Mathisen M, Basnet S, Sharma A, Shrestha PS, Sharma BN, et al. (2011) RNA viruses in young Nepalese children hospitalized with severe pneumonia. Pediatr Infect Dis $J$ 30: 1032-1036. [Crossref]

51. Venter M, Madhi SA, Tiemessen CT, Schoub BD (2001) Genetic diversity and molecular epidemiology of respiratory syncytial virus over four consecutive seasons in South Africa: identification of new subgroup A and B genotypes. J Gen Virol 82: $2117-2124$.
52. McLellan JS, Chen M, Kim A, Yang Y, Graham BS, et al. (2010) Structural basis of respiratory syncytial virus neutralization by motavizumab. Nat Struct Mol Biol 17: 248250. [Crossref]

53. Navarini AA, Recher M, Lang KS, Georgiev P, Meury S, et al. (2006) Increased susceptibility to bacterial superinfection as a consequence of innate antiviral responses. Proc Natl Acad Sci U S A 103: 15535-15539.

Copyright: (C2017 Fall A. This is an open-access article distributed under the terms of the Creative Commons Attribution License, which permits unrestricted use, distribution, and reproduction in any medium, provided the original author and source are credited. 